\title{
Awareness of mycotoxins and occurrence of aflatoxins in poultry feeds and feed ingredients in selected regions of Uganda
}

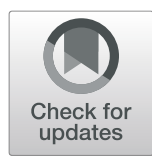

Jesca L. Nakavuma ${ }^{1,2^{*}}$, Angella Kirabo ${ }^{3,4}$, Paul Bogere ${ }^{1}$, Margaret M. Nabulime ${ }^{1,2}$, Archileo N. Kaaya ${ }^{3}$ and Benoit Gnonlonfin ${ }^{5}$

\begin{abstract}
Background: Aflatoxins are a category of mycotoxins produced by certain molds naturally occurring as food and feed contaminants with toxic effects to both animals and humans. In Uganda, previous studies on aflatoxins mainly considered human foods, but scarce information exists for animal feeds. The study aimed at establishing the current status of aflatoxins contamination of poultry feeds, level of awareness and the existing technological challenges and innovations to mycotoxin control in Uganda.

Method: Mycotoxin awareness, predisposing factors and existing strategies for managing mycotoxin contamination were investigated through focus group discussions and questionnaires with selected processors and farmers.

Poultry feed and feed ingredient samples were collected and analyzed for total aflatoxins using VICAM Fluorimeter procedure for foods and animal feeds.

Results: Majority of the farmers and processors (> 50\%) had limited knowledge about aflatoxins; contamination predisposing factors; dangers to animals and humans; and mitigation strategies. The study further revealed poor feed and feed ingredients handling and storage practices that predispose to mold/aflatoxin contamination. Forty feed samples from feed processing plants had aflatoxins in the range $7.5 \pm 0.71$ to $393.5 \pm 19.09$ parts per billion (ppb) with only twelve samples being within the generally acceptable limits of $20 \mathrm{ppb}$ as recommended by the Food and Agricultural Organisation and the United States Federal Department of Agriculture. Additionally, all 27 feed samples obtained from the farmers had aflatoxins in the range of $19.0 \pm 1.41$ to $188.5 \pm 2.12 \mathrm{ppb}$ and were above the acceptable limit. Generally, broiler feeds were the most contaminated with aflatoxins. Of the feed ingredients tested, silver fish (Rastrineobola argentea, locally known as "mukene") had the least concentration (8.7 \pm $3.18 \mathrm{ppb}$ ) of aflatoxins while maize bran had the highest level of contamination, $103.3 \pm 22.98 \mathrm{ppb}$.

(Continued on next page)
\end{abstract}

\footnotetext{
* Correspondence: JLNakavuma@covab.mak.ac.ug;

Jesca.Nakavuma@gmail.com

${ }^{1}$ College of Veterinary Medicine, Animal Resources and Biosecurity, Makerere

University, Kampala, Uganda

VMT Consults (U) Limited, Plot 253 Kansanga, P.O. Box 29757, Kampala,

Uganda

Full list of author information is available at the end of the article
}

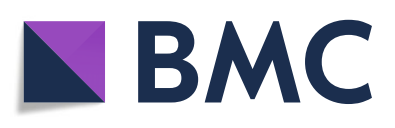

(- The Author(s). 2020 Open Access This article is licensed under a Creative Commons Attribution 4.0 International License, which permits use, sharing, adaptation, distribution and reproduction in any medium or format, as long as you give appropriate credit to the original author(s) and the source, provide a link to the Creative Commons licence, and indicate if changes were made. The images or other third party material in this article are included in the article's Creative Commons licence, unless indicated otherwise in a credit line to the material. If material is not included in the article's Creative Commons licence and your intended use is not permitted by statutory regulation or exceeds the permitted use, you will need to obtain permission directly from the copyright holder. To view a copy of this licence, visit http://creativecommons.org/licenses/by/4.0/. The Creative Commons Public Domain Dedication waiver (http://creativecommons.org/publicdomain/zero/1.0/) applies to the data made available in this article, unless otherwise stated in a credit line to the data. 
(Continued from previous page)

Conclusion: Given the lack of awareness and the high prevalence of aflatoxin contaminated poultry feeds and feed ingredients in Uganda, a higher risk for carryover of the toxins into the animal products for human consumption exist. Hence, the need for comprehensive establishment of the prevention, control and surveillance strategies for reducing mycotoxins in foods.

Keywords: Aflatoxin, Poultry feed, Feed ingredients, Processor, Farmers

\section{Introduction}

Animal feed contamination with mycotoxins due to mold growth on living and stored plants presents a global challenge to farmers (Moretti et al. 2017). The most common mycotoxins include; aflatoxins, ochratoxin A, trichothecenes, zearalenone, and fumonisins. Aflatoxins are not as prevalent at pre-harvest stages as some other mycotoxins; since the associated fungi are commonly considered storage molds (Afolabi et al. 2019; Leggieri et al. 2020). Aflatoxins are mainly produced by Aspergillus flavus and Aspergillus parasiticus, which are especially found in areas with hot and humid climates; and are hence frequent contaminants of agricultural products from tropical countries, such as Uganda (EFSA 2019). The greatest bulk of animal and poultry feeds is composed of raw materials that are mainly cereal based; and these are often prone to contamination by mycotoxin-producing fungi. Moreover, in a review by Bankole et al. (2006), it was pointed out that maize and groundnuts are the most contaminated crops with Aspergillus spp. in Sub Saharan Africa. Additionally, previous studies reported Ugandan crops, mainly maize, peanuts and cassava, having aflatoxins at unacceptable levels, with some samples recording as high as $1000 \mathrm{ppb}$ (Kaaya and Kyamuhangire 2006; Lukwago et al. 2019; Muzoora et al. 2017). Similarly, the presence of aflatoxins and non-regulated fungal metabolites in maize across the different seasons was reported elsewhere (Hajnal et al. 2020).

Pre- and post- harvest aflatoxin contamination is widely associated with food crops including groundnuts, maize, tree nuts, rice, figs, dried foods, cocoa beans, fruits, spices, crude vegetable oils, as well as milk, and meat products (Iqbal et al. 2015; Moretti et al. 2017; Udomkun et al. 2017). Cowpeas, which is widely promoted as a protein source in human feeds; and may be utilized in animal feed formulations are also prone to fungal infestations and mycotoxin contamination (Afolabi et al. 2019). Essentially, raw materials for compound food and feeds are good substrates for mold growth; and Food and Agricultural Organisation (FAO) estimated up to $25 \%$ of the world's food crops and a big proportion of the world's animal feedstuffs being contaminated by mycotoxins (Streit et al. 2013). Aflatoxins have toxic, carcinogenic, mutagenic and teratogenic effects in the humans and animals; with predilection to the liver (Milicevic et al. 2015; Zain 2011). Aflatoxin-contamination along the animal feed chain, is not generally given attention especially in developing countries, however, it contributes to exposure of the human consumers to contaminated products (Akande et al. 2006; Ráduly et al. 2020). Aflatoxins are associated with economic impacts including increased mortality of farm animals, lowered livestock productivity, increased veterinary costs and challenges in disposal of contaminated feeds and feed ingredients (Akande et al. 2006; Zain 2011). In addition to the effects of the aflatoxins, mold-infested feeds have poor nutritional value and organoleptic properties, which affect feed intake by the animals (Akande et al. 2006).

Poor post-harvest and produce handling practices, which are commonly encountered in Uganda, favor growth of molds and subsequent production of mycotoxins. Most of the data on aflatoxins in Uganda, relate to foods for human consumption (Kaaya and Warren 2005; Taligoola et al. 2010; Taligoola et al. 2011). However, there is evidence of high levels of aflatoxins in animal feeds (Kaaya et al. 2000). Information on aflatoxin levels in poultry feeds remains scarce; yet contaminated animal products are a major source of exposure to the human consumers (Ráduly et al. 2020). Apart from institution of various control strategies, successful management of aflatoxins requires awareness by the various stakeholders. However, there is a knowledge gap about awareness by farmers and feed processors as well as the practices that contribute to aflatoxins contamination. Therefore, the purpose of this study was to establish the current status of aflatoxins contamination of poultry feeds, level of awareness by the farmers and feed processors; and the existing technological challenges and innovations to mycotoxin control in Uganda.

\section{Materials and methods}

\section{Study area, population and samples}

The study population included selected small- and largescale feed processors, and poultry farmers in the districts of Kampala, Wakiso, Jinja, Mbale and Masindi. The farmers were identified by the Uganda Poultry Farmers' Association (UPOFAN). For establishing awareness and feed handling practices, 44 respondents (17 farmers and 27 processors) from Kampala, Wakiso and Jinja districts were selected. 
The poultry feed samples and feed ingredients were sourced from selected commercial feed processors from all the five districts, while additional samples of on-farm mixed feeds were obtained from three (3) farmers located in each of the three (3) agro-ecological zones of Uganda (mid-altitude wet [Jinja], mid-altitude dry [Masindi], and high altitude [Mbale]) where high occurrence of mycotoxins was reported (Atukwase et al. 2009).

\section{Feed sampling}

From each firm or farm, one feed sample was collected and analysed in duplicate. However, in case of poultry farms, a composite feed sample was obtained. The sample sources included selected commercial feed processors (four large scale and four small scale); and nine farmers (three farmers, three agro-ecological zones). The feed types included chick mash, growers mash, layers mash, broiler starter and broiler finisher; however, three feed types were collected from the farmers, due to the type and age of the poultry kept at the time. In addition to the compound feeds, one sample of each of the feed ingredients (silver fish/mukene, maize bran, cotton seed cake, sunflower seed cake, and soybean) were obtained from four of the eight selected processors. Hence, a total of 67 feeds and 20 feed ingredients samples from both processors and farmers were analyzed in duplicate for presence and levels of aflatoxins.

\section{Mycotoxin awareness surveys}

Mycotoxin awareness, predisposing practices during feed handling and/or processing and existing strategies for mycotoxin contamination were investigated through focus group discussions (FGDs) with the processors; and a questionnaire survey and check lists with selected farmers. Some of the farmers and processors were engaged at their sites of operations to get information in relation to a summary presented in Table 1 . Use of mycotoxin binders was also probed for. For each study area, after the FGD's and questionnaire administration, a sensitization seminar on the mycotoxins, their causes, predisposing factors and preventative strategies was

Table 1 Information sought for through the questionnaire

1. Location
2. Respondent demographic information
3. Bird species and categories kept
4. General knowledge on aflatoxins or mycotoxins
5. Feed or ingredient purchasing practices
6. Feed or ingredients storage practices and problems
7. Strategies for prevention of storage problems
8. Knowledge about mycotoxin binders

offered. The checklist of questions used for FGDs are presented in Table 2.

\section{Laboratory analysis for aflatoxins Extraction of Aflatoxins}

The aflatoxin content in the feeds and feed ingredients was determined at the Department of Food Technology and Nutrition, Makerere University, using the VICAM Fluorimeter procedure for foods and animal feeds, following the manufacturer's instructions (VICAM L. P, USA). The aflatoxins were extracted following a procedure as described by Kaaya et al. (2000) and the filtrate was stored at $-18^{\circ} \mathrm{C}$ for later use. Briefly, the fluorimeter was calibrated using Aflatest ${ }^{\oplus}$ Federal Grain Inspection Service (FGIS) standards. The Aflatest developer solution was prepared; as well as an aflatoxin extraction solution, $80 \%$ methanol (methanol:water 80:20 v/v). All the samples were ground using a Romer Mill (Romer series $\mathrm{II}^{\odot}$ MILL), and from each sample $50.0 \mathrm{~g}$ was weighed, mixed with $5 \mathrm{~g}$ Sodium Chloride; to which 100 $\mathrm{ml}$ of the extraction solution was added and blended at high speed for $1 \mathrm{~min}$. The mixture was filtered through a fluted filter paper (Folder Grade: 1289, VICAM, A Waters Business), $10 \mathrm{ml}$ of filtrate was diluted with $20 \mathrm{ml}$ of purified water in a clean tube and mixed properly. The diluted solution $(5 \mathrm{ml})$ was filtered through $1.5 \mu \mathrm{m}$ microfiber glass and then passed through an AflaTest column, which was attached to a VICAM stand. The column was washed twice with $10 \mathrm{ml}$ of purified water at a rate of 1-2 drops/second; a process that was repeated until air passed through the column. To the column head-space, $1 \mathrm{ml}$ of High Performance Liquid Chromatography (HPLC) grade methanol was added to elute the aflatoxin from the column at a rate of 1 drop/ second into the glass cuvette.

\section{Aflatoxin quantification}

One $\mathrm{mL}$ of Aflatest $^{\oplus}$ developer solution was added to the eluate, mixed, and concentrations of total aflatoxin (B1+ $\mathrm{B} 2+\mathrm{G} 1+\mathrm{G} 2)$ in $\mu \mathrm{g} / \mathrm{kg}$ were detected after $60 \mathrm{~s}$ using a Vicam fluorometer (Series-4EX, Source Scientific LLC, USA), which was calibrated with methanol as the blank.

Table 2 Checklist of questions for the Focus group discussions (FGDs)

1. Challenges associated with animal feeds. Please prioritize the
challenges identified
2. Mycotoxins awareness:
a. Source of information
b. Implications to humans and animals
c. Other implications (trade etc.)
3. Strategies for mycotoxins management
4. Suggest what works well for you.


The lower detection limit of this method was $1.0 \mu \mathrm{g} / \mathrm{kg}$ and upper limit was $200 \mu \mathrm{g} / \mathrm{kg}$. For samples above $200 \mu \mathrm{g} / \mathrm{kg}$, extracts were further diluted an additional $\times 5$ for an upper limit of $1000 \mu \mathrm{g} / \mathrm{kg}(1 \mu \mathrm{g} / \mathrm{kg}=1 \mathrm{ppb})$.

\section{Statistical analysis}

Differences in knowledge between the farmers and processors were compared using Mann-Whitney $U$ test in STATA (version 12.0). The aflatoxin contamination levels were compared by, feed types, feed ingredients and whether sourced from processor or farmer. Data were summarized and expressed as means. Differences in aflatoxin contamination was analyzed using analysis of variance (ANOVA). Duncan's multiple range test was used to test for differences between the specific categories and $p<0.05$ was set to indicate statistical significance. Analyses were performed using $\mathrm{SAS}^{\circ}$ software (version 9.1, 2004; SAS Institute, USA).

\section{Results}

Mycotoxin awareness among selected poultry farmers and feed processors

Findings about the farmers and processors' awareness on mycotoxins in poultry feeds are summarized in
Table 3. Knowledge levels on mycotoxins including awareness, occurrence, predisposing factors, effects to animals and humans, as well as preventive measures generally ranked between 0 and 6 with a mean of $2.65 \pm$ 1.92. There was no significant difference $(p>0.05)$ observed between the farmers and processors for most of the tested parameters except knowledge on preventive measures where processors were more knowledgeable $(p<0.05)$ compared to farmers. However, poultry farmers were more aware $(52.94 \%)$ of mycotoxins and their occurrence compared to feed processors (44.44\%). An almost equal number of farmers and processors did not have any knowledge on factors influencing mycotoxin contamination and its dangers.

Table 4 present the results of the survey on the factors predisposing to mycotoxins in poultry feeds, broadly categorized into: general feed storage and feed purchasing. All the 44 respondents practiced stock piling of the feeds and feed ingredients especially maize bran $(81.8 \%)$ in preparation for seasons of scarcity. Majority $(88.6 \%)$ of the respondents reported having encountered molds in their feeds and ingredients during storage while $72.7 \%$ did not practice the first-in first-out good store management practice. Many (56.8\%) of the respondents did not

Table 3 Mycotoxin awareness among selected poultry farmers and feed processors

\begin{tabular}{|c|c|c|c|c|c|}
\hline Knowledge Parameter & Response & $\begin{array}{l}\text { Total (\%) } n= \\
44\end{array}$ & $\begin{array}{l}\text { Farmers (\%) } n= \\
17\end{array}$ & $\begin{array}{l}\text { Processors (\%) } n= \\
27\end{array}$ & $\begin{array}{l}P \\
\text { value }\end{array}$ \\
\hline \multirow[t]{2}{*}{ Awareness of mycotoxins } & Yes & $21(47.73)$ & 52.94 & 44.44 & \multirow[t]{2}{*}{0.758} \\
\hline & No & $23(52.27)$ & 47.06 & 55.56 & \\
\hline \multirow[t]{2}{*}{ Occurrence } & Yes & $19(43.18)$ & 52.94 & 37.04 & \multirow[t]{2}{*}{0.359} \\
\hline & No & $25(56.82)$ & 47.06 & 62.96 & \\
\hline \multirow[t]{4}{*}{ Factors influencing mycotoxin contamination } & Rodents/Insects/Molds & $5(11.36)$ & 11.76 & 11.11 & \multirow[t]{4}{*}{0.145} \\
\hline & $\begin{array}{l}\text { Poor harvesting/ } \\
\text { Handling }\end{array}$ & $3(6.82)$ & 17.65 & 0.00 & \\
\hline & Moisture & $12(27.27)$ & 17.65 & 33.33 & \\
\hline & Do not know & $24(54.55)$ & 52.94 & 55.56 & \\
\hline \multirow[t]{4}{*}{ Dangers of mycotoxin contamination } & Few eggs & $5(11.36)$ & 23.53 & 3.70 & \\
\hline & III-health & $4(9.09)$ & 5.88 & 11.11 & \multirow[t]{3}{*}{0.165} \\
\hline & Poor growth & $10(22.73)$ & 11.76 & 29.63 & \\
\hline & Do not know & $25(56.82)$ & 58.82 & 55.56 & \\
\hline \multirow[t]{5}{*}{ Solution to mycotoxin contamination } & Drying & $19(43.18)$ & 35.29 & 48.15 & \multirow[t]{5}{*}{0.044} \\
\hline & Mixing own feed & $3(6.82)$ & 17.65 & 0.00 & \\
\hline & Sorting & $1(2.27)$ & 0.00 & 3.70 & \\
\hline & Pesticide & $8(18.18)$ & 5.88 & 25.93 & \\
\hline & Do not know & $13(29.55)$ & 41.18 & 22.22 & \\
\hline \multirow{2}{*}{$\begin{array}{l}\text { Awareness of mycotoxin effects to humans and } \\
\text { animals }\end{array}$} & Yes & $7(15.91)$ & 23.53 & 11.11 & \multirow[t]{2}{*}{0.402} \\
\hline & No & $37(84.09)$ & 76.47 & 88.89 & \\
\hline \multirow[t]{2}{*}{ Overall knowledge score } & Range & $0-6$ & & & \\
\hline & Mean $\pm S D$ & $2.65 \pm 1.92$ & $2.76 \pm 1.75$ & $2.59 \pm 2.06$ & 0.7357 \\
\hline
\end{tabular}

Differences in knowledge between the farmers and processors were compared using Mann-Whitney $\mathrm{U}$ test with being significant at $p<0.05$ 
Table 4 The feed acquisition and storage practices among selected poultry farmers and feed processors

\begin{tabular}{|c|c|c|c|}
\hline & Category & Response & Frequency (\%) $\boldsymbol{n}=44$ \\
\hline \multirow[t]{19}{*}{ Storage Practices } & \multirow[t]{3}{*}{ Reasons for stock piling feed/ingredients } & Preparation for period of scarcity & $26(59.1)$ \\
\hline & & Favourable/lower prices & $16(36.4)$ \\
\hline & & Others (own harvest) & $2(4.5)$ \\
\hline & \multirow[t]{2}{*}{ Average duration of storage } & $<1$ month & $26(59.1)$ \\
\hline & & $>1$ month & $18(40.9)$ \\
\hline & \multirow[t]{2}{*}{ Form stored } & Individual ingredients, especially maize bran & $36(81.8)$ \\
\hline & & Mixed & $8(18.2)$ \\
\hline & \multirow[t]{3}{*}{ Quantity stored (kg) } & $<100$ & $18(40.9)$ \\
\hline & & $100-1000$ & $33(75.0)$ \\
\hline & & $>1000$ & $3(6.8)$ \\
\hline & \multirow[t]{2}{*}{ Structure of storage area } & Raised platform & $12(27.3)$ \\
\hline & & On floor & $32(72.7)$ \\
\hline & \multirow[t]{2}{*}{ Ever encountered storage problems } & Yes & 39 (88.6) \\
\hline & & No & $5(11.4)$ \\
\hline & \multirow[t]{3}{*}{ Storage problem management } & Fumigation & $31(70.5)$ \\
\hline & & Proper drying & $9(20.5)$ \\
\hline & & Binder & $4(9.1)$ \\
\hline & \multirow[t]{2}{*}{ Practice First in-First out } & Yes & $12(27.3)$ \\
\hline & & No & $32(72.7)$ \\
\hline \multirow[t]{15}{*}{ Feed Purchasing Practices } & \multirow[t]{3}{*}{ Feed Source } & Local supplier & $7(15.9)$ \\
\hline & & Commercial processor & $26(59.1)$ \\
\hline & & Other & $11(25.0)$ \\
\hline & \multirow[t]{4}{*}{ Ingredient source } & Small scale feed traders in Kisenyi & $14(31.8)$ \\
\hline & & Local miller/supplier & $13(29.5)$ \\
\hline & & Local Processor/agent & $8(18.2)$ \\
\hline & & Other & $9(20.5)$ \\
\hline & \multirow[t]{5}{*}{ Quality determination method } & Source from reliable source & $2(4.5)$ \\
\hline & & Inspect for foreign objects & $16(36.4)$ \\
\hline & & Appearance, not moldy & $8(18.2)$ \\
\hline & & Moisture check (subjective) & 17 (38.6) \\
\hline & & Other & $1(2.3)$ \\
\hline & \multirow[t]{3}{*}{ Source from same supplier } & Yes & $5(11.4)$ \\
\hline & & No & $25(56.8)$ \\
\hline & & Other (price influence) & $14(31.8)$ \\
\hline
\end{tabular}

purchase feeds from the same supplier while $31 \%$ obtained their feeds from other sources as determined by the prevailing market prices.

\section{Occurrence and concentration of Aflatoxins in poultry feeds and feed ingredients}

Feeds of different types including; chick mash, growers mash, broiler mash, layers mash and broiler finisher from large scale and small-scale processors were each tested for presence and concentration of aflatoxins. All 40 feed samples from the processors that were analyzed contained aflatoxins ranging from $24.75 \pm 13.99$ to $185.25 \pm 142.03 \mathrm{ppb}$ irrespective of the scale of the processor (Table 5). Only six feed samples had aflatoxin concentration within FAO (2004)/USFDA (2019) acceptable limits of 20 ppb. It should be noted that four samples of those that were in acceptable limits were from one large scale commercial processor from Wakiso district while the remaining seven processors had aflatoxin levels higher than $20 \mathrm{ppb}$. Generally, large scale processors had significantly lower levels of aflatoxins in the tested feed types than their small-scale counterparts, at $p<$ 0.05; except for grower's marsh (Table 5). 
Table 5 Occurrence and aflatoxin concentrations in different poultry feed types from large- and small-scale processors

\begin{tabular}{|c|c|c|c|c|c|}
\hline \multirow{2}{*}{$\begin{array}{l}\text { Processor's } \\
\text { scale of } \\
\text { production }\end{array}$} & \multicolumn{5}{|c|}{ Aflatoxin concentration Mean \pm SD (ppb) } \\
\hline & Chick mash & Growers Mash & Broiler Finisher & Layers mash & Broiler mash \\
\hline Large scale & $26.75 \pm 11.85^{b}$ & $86.5 \pm 116.54^{a}$ & $46.50 \pm 23.23^{b}$ & $40.40 \pm 31.50^{b}$ & $24.75 \pm 13.99^{b}$ \\
\hline Small scale & $69.38 \pm 16.24^{a}$ & $125.87 \pm 96.74^{a}$ & $185.25 \pm 142.03^{\mathrm{a}}$ & $98.38 \pm 79.08^{\mathrm{a}}$ & $105.37 \pm 125.34$ \\
\hline
\end{tabular}

Data represents Mean \pm standard deviation of 4 samples from 4 processors of each category

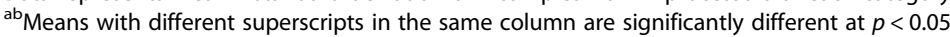

At farmer level, compounded feeds (chick mash, growers mash and broiler finisher) were analyzed for aflatoxin contamination. All 27 feed samples from the nine farmers had aflatoxin levels in the range $19.0 \pm 1.41$ to $188.5 \pm 2.12 \mathrm{ppb}$, which was above the acceptable limit of $20 \mathrm{ppb}$. Aflatoxin concentration in poultry feeds collected from the farms differed significantly $(p<0.05)$ amongst the farmers with those from Wakiso district having higher concentration compared to those from Mbale and Masindi (Fig. 1).

Results for presence and levels of aflatoxins in the feed ingredients from two large scale and two small scale processors are shown in Table 6. Aflatoxin concentration varied significantly $(p<0.05)$ across the different feed ingredients with silver fish having the least concentration and maize bran the highest levels. The order of contamination thus followed the trend; Silver fish $<$ Soybean $<$ Sunflower $<$ Cotton seed cake $<$ Maize bran. The various feed ingredients types sourced from small scale processors had higher concentrations of aflatoxins compared to those obtained from the large-scale processors. One large scale processor, had all feed ingredients within the FAO (2004) accepted range $(<20 \mathrm{ppb})$ with the lowest (Silver fish) having $6.5 \pm 0.71 \mathrm{ppb}$ and highest, maize bran, having $18 \pm 2.83 \mathrm{ppb}$ (data not shown). Generally, small scale processors had feed ingredients with significantly $(p<0.05)$ higher aflatoxins concentration compared to the large-scale processors; except for Silver fish and cotton seed cake.

\section{Discussion}

Presence of aflatoxins in poultry feeds and feed ingredients compromises farm production parameters including feed intake, feed conversion, weight gain, reproductive performance of the birds; and at the same time risking the introduction of these toxins into the human food chain (Nemati et al. 2014; Ráduly et al. 2020). Investigation of practices, knowledge and apparent health risk to

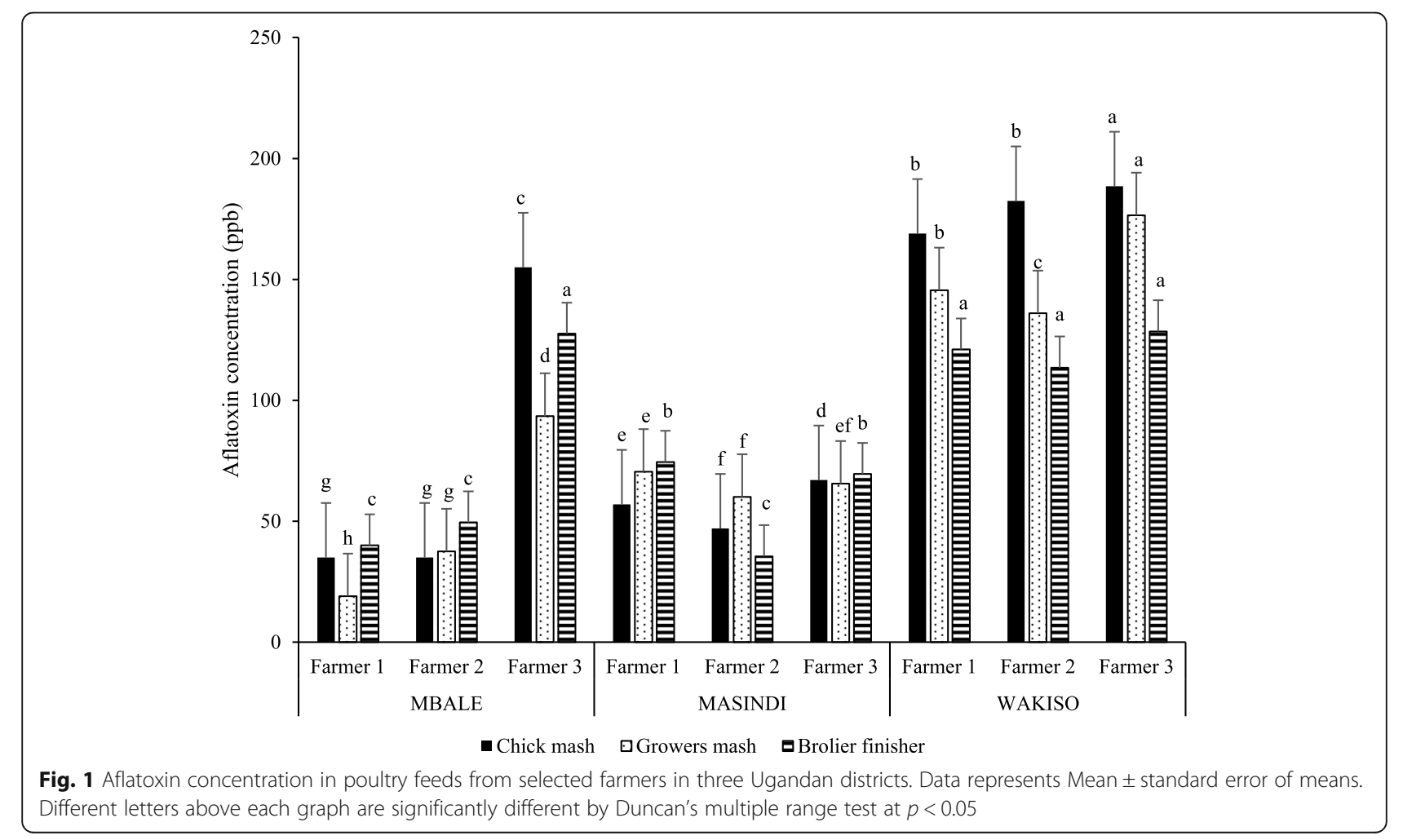


Table 6 Aflatoxin concentration in different poultry feed ingredients from large- and small-scale processors

\begin{tabular}{|c|c|c|c|c|c|}
\hline \multirow{2}{*}{$\begin{array}{l}\text { Processor's } \\
\text { scale of } \\
\text { production }\end{array}$} & \multicolumn{5}{|c|}{ Aflatoxin concentration Mean \pm SD (ppb) } \\
\hline & Mukene & Maize bran & Soybean & Cotton seed & Sunflower seed \\
\hline Large scale & $8.75 \pm 3.18^{\mathrm{a}}$ & $22.25 \pm 6.01^{b}$ & $16.75 \pm 7.42^{b}$ & $20.25 \pm 6.71^{a}$ & $17.00 \pm 7.78^{b}$ \\
\hline Small scale & $19.25 \pm 5.30^{\mathrm{a}}$ & $103.25 \pm 22.98^{\mathrm{a}}$ & $52.75 \pm 0.35^{\mathrm{a}}$ & $67.25 \pm 22.98^{\mathrm{a}}$ & $62.25 \pm 2.47^{\mathrm{a}}$ \\
\hline
\end{tabular}

Data represents Mean \pm standard deviation of two samples from two processors of each category

${ }^{a b}$ Means with different superscripts in the same column are significantly different at $p<0.05$

humans and animals by aflatoxins amongst the key stake holders in the animal food chain including poultry farmers and feed processors is paramount to establish awareness levels if prevention strategies are to be established. The current study revealed low levels of knowledge on aflatoxins among poultry farmers and feed processors. However, farmers were more knowledgeable compared to the processors. This finding contrast that by Kang'ethe and Lang'a (2009) who reported $67 \%$ of the urban farmers not knowing the existence of aflatoxins in grains while feed millers were knowledgeable even about its excretion in milk, although there were no measures taken to reduce exposure to the animals. A similar study by Makau et al. (2016) reported about $38.5 \%$ of the famers being aware of aflatoxicosis in dairy cows; while Marechera and Ndwiga (2014) reported a higher percentage (92.5\%) of farmers in the lower eastern Kenya to have knowledge about aflatoxins. For the latter, their knowledge was, however, influenced by the fact that their area had registered a number of aflatoxin outbreaks in humans during previous years and aflatoxin contamination is regarded endemic. For this study, processors were more knowledgeable about some aspects of mycotoxins prevention strategies than farmers; and some reported use of 'binders', such as Toxiban ${ }^{\circ}$. However, they thought that the purpose of the binders was to improve the shelf-life; and/or kill the storage pests or as growth promotion supplements. The survey further revealed poor storage practices, such as, stock piling and storing feeds on the floor. Stock piling and other poor bulk handling practices of feeds, including prolonged time in storage, predisposes to contamination of feed stuffs with aflatoxin producing fungi (Cheat et al. 2016; Makau et al. 2016). Moreover, stock piling and direct storage of feeds/ingredients on the floor increases the dampness and moisture content, while the pressure exerted by feeds upon each other leads to reduced feed particle sizes hence creating conditions favorable for mold growth (Munthali et al. 2016). Poor storage of feeds and feed ingredients, for example maize bran, maize germ and other grain mill products, has been associated with contamination by aflatoxins (Lanyasunya et al. 2005). Non practice of the first-in first-out store management as observed in this study leads to farmers and processors blending old batches of feeds and feed ingredients with new ones, a phenomenon that increases the risk of aflatoxin contamination. Surprisingly, deliberate use of poorquality maize and recycling of moldy grain products, such as bread, into animal feeds was reported by some smallscale processors. This practice is likely to be a substantial source of molds and mycotoxin contamination to the final product. Results of the survey points to the fact that lack of knowledge fails risk management efforts, hence the need for education or sensitization to create awareness as well as institution of behavioral change.

The present study revealed a generally high contamination of broiler feeds with aflatoxins, similar to findings by Kana et al. (2013) who reported levels of 39-950 ppb and $2-23 \mathrm{ppb}$, for broiler feeds and layer feeds, respectively. Similar results for broiler mash contamination were reported by Kajuna et al. (2013). All feed samples sourced from the farmers in the present study had aflatoxins concentrations beyond the acceptable limits. These findings are similar to those from a related study in Kenya by Kang'ethe and Lang'a (2009) who reported $67 \%$ and $58 \%$ of the aflatoxins positive samples from farmers and grain millers, respectively; exceeding the FAO recommended limits. An assessment of aflatoxins concentration in mixed poultry feeds in Cameroon showed that $93.3 \%$ of broiler and $83 \%$ of layer feeds tested positive for aflatoxins (Kana et al. 2013), which augments findings in our study. An earlier investigation in Uganda by Sebunya and Yourtee (1990) reported that $66.6 \%$ of the poultry feed and $83.3 \%$ of other animal feeds had high levels of aflatoxins, pointing to the persistent occurrence of the problem. The lower levels of aflatoxins in poultry feed types from large scale processors compared to those from small scale processors is influenced by the improved processing and storage facilities as well as the short holding duration among the former category. Most of the small-scale processors have semi-permanent buildings that are porous, hence there is no effective management of humidity levels and entry of vermin, which predispose to contamination. The high humidity levels in the study area in Uganda, postharvesting challenges as well as the feed and feed ingredient handling practices by both the processors and farmers could explain the high occurrence of aflatoxins contamination of the samples analyzed as earlier 
reported by previous researchers (Kaaya and Warren 2005; Kotinagu et al. 2015).

The bulk of poultry feeds in Uganda is majorly composed of silver fish, maize bran, soybean, cotton seed and sunflower seed cake. Analysis of aflatoxins concentration in the raw materials showed that the fish meal was least contaminated while maize bran was most contaminated. Despite the similarity in contamination levels in the various feed types as observed in the present study and those reported elsewhere in the region, the trend in the feed ingredients is different (Kana et al. 2013; Nemati et al. 2014). Nemati et al. (2014) reported soybean contamination levels of $6.01 \mathrm{ppb}$ whereas maize grains and wheat bran had $2.35 \mathrm{ppb}$ and $3.05 \mathrm{ppb}$, respectively. Kajuna et al. (2013) also reported minimal contamination of maize bran despite most feed samples testing positive for aflatoxin B1. Similar to the current findings, Nyangi et al. (2016) reported high concentration of aflatoxins in maize bran used for animal feed compared to other maize based products on the market in Tanzania. Due to the ubiquitous nature of aflatoxigenic molds in the environment, feed ingredients often get contaminated before or after harvest during storage, mixing and compounding into whole feed (Kajuna et al. 2013). Feed processing methods, specifically thermal treatment is done in case of soybean, but not any other ingredients that are only crushed into smaller particles. The treatment probably influenced the low aflatoxins content in soybean, although the detection method targeted the primary aflatoxins not the degradation products, which may be equally toxic (Stadler et al. 2019). Occurrence of aflatoxins in feed ingredients and raw materials even at lower concentrations will result into overall contamination of the compounded feed posing health risk to the animals (Nemati et al. 2014). Since maize bran forms the highest proportion in the feed formulation, there is need to manage field and storage maize contamination, to ensure safety along the food/feed value chain; and prevent carryover in animal products for human consumption.

\section{Conclusions}

The present study revealed low levels of knowledge about mycotoxins in poultry feed by both feed processors and farmers since majority $(>50 \%)$ were not aware of these toxins, their occurrence, predisposing factors and dangers to both animals and humans. The study further revealed poor feed and feed ingredients handling and storage practices that predispose to mold/aflatoxin contamination. All the feed samples from feed processing plants were contaminated with aflatoxins, but only $18.8 \%$ were within the recommended limit of $20 \mathrm{ppb}$ (FAO 2004 /USFDA 2019). Similarly, all the feed samples from the farmers were contaminated with aflatoxins but none was within the acceptable limits; and broiler feeds were more contaminated than the other feed categories. Of the feed ingredients tested, the silver fish had the least concentration of aflatoxins while maize bran had the highest level of contamination. Hence efforts to manage aflatoxins should emphasize the maize value chain.

The limited awareness and the high prevalence of aflatoxin contaminated poultry feeds in Uganda, points to a higher risk for human consumers; hence sensitization of the relevant stakeholders is necessary. Additionally, as it has been proposed in many other African countries, there is need for comprehensive establishment of the prevention, control and surveillance strategies for reducing mycotoxins, especially the aflatoxins, in feeds. Finally, in order to estimate the impact and hazards on animal and human health, there is need to carry out exposure assessment of aflatoxin intake through consumption of maize-based foods and feeds, as it was done for wheat-based foods (Djekic et al. (2019).

\section{Abbreviations}

$\mu \mathrm{g} / \mathrm{kg}$ : Microgram per kilogram; ANOVA: Analysis of variance;

CGS: Competitive Grant Scheme; ECOWAS: Economic Community of West African States; EFSA: European Food Safety Authority; et al.: Et alia (and others); FAO: Food and Agricultural Organisation; FGDs: Focus Group Discussions; FGIS: Federal Grain Inspection Service; HPLC: High Performance Liquid Chromatography; L: Large scale poultry feed processor; min: Minute; ml: Millilitre; NARO: National Agricultural Research Organisation; P: Small scale poultry feed processor; ppb: Parts per billion; SPS: Sanitary and Phytosanitary; UPOFAN: Uganda Poultry Farmers Network; USAID: United States Agency for International Development; USFDA: United States Food and Drug Administration; v/v: Volume per volume

\section{Acknowledgements}

We are thankful to the National Agricultural Research Systems-Competitive Grant Scheme 2013/2014 for funding this work. The agricultural extension of ficers, the poultry farmers and the feed processors in Mbale, Masindi, Jinja, Wakiso and Kampala districts, who participated in this study are greatly acknowledged.

\section{Authors' contributions}

$J L N, A N K, M M N$ and BG conceptualised the research proposal and study design; JLN, ANK, MMN and AK were involved in data acquisition including feed sample collection; AK and ANK were involved in laboratory analyses and interpretation; JLN and PB were involved in the first manuscript draft preparation; PB carried out the statistical analyses, and prepared the subsequent versions of the manuscript. All the authors read and approved the final version for submission.

\section{Authors' information}

1. JLN holds a PhD, is a Senior Lecturer and Microbiologist, College of Veterinary Medicine, Animal Resources and Biosecurity, Makerere University P. O. Box 7062, Kampala, Uganda. Director VMT consults, an NGO, e-mail: JLNakavuma@covab.mak.ac.ug and Jesca.Nakavuma@gmail.com

2. AK, graduate student of MSc Food Science and Technology at the College of Agricultural and Environmental Sciences, Makerere University; and Researcher at Uganda Industrial Research Institute, Plot M45 Nakawa Industrial Area; e-mail: angelarwaheru@gmail.com.

3. $\mathrm{PB}$, holds a Bachelors of Veterinary Medicine, MSc degree in Agriculture; has experience in data analysis and probiotic research for animal production; e-mail: spbogere1@gmail.com 
4. MMN, holds an MSc in Feed Technology, and is the Principal Technologist in charge of the Nutrition Laboratory, College of Veterinary Medicine, Animal Resources and Biosecurity, Makerere University P. O. Box 7062, Kampala, Uganda. Director VMT consults, an NGO; e-mail: nabulime.mary@gmail.com

5. ANK is a Professor of Food Science and Technology, at the College of Agricultural and Environmental Sciences, Makerere University. Has vast experience in mycotoxins especially, aflatoxins and is a member of the Pan African group - Partnership for Aflatoxin Control in Africa (PACA). E-mail: kaaya.archileo48@gmail.com

6. BG holds a PhD in Food Microbiology, ECOWAS-USAID Senior Sanitary and Phytosanitary (SPS) standards advisor, in Abuja, Nigeria. He was formerly BecA-ILRI Hub Postdoctoral Scientist researching on Aflatoxins; and a member of PACA. E-mail: bgnonlonfin74@gmail.com

\section{Funding}

This study was part of the research project entitled "Development of a Biological Mycotoxin-Binder for Improving the Safety of the Livestock Feeds and Animal Productivity", referenced as CGS/2/17/14. The project was supported under the National Agricultural Research Systems-Competitive Grant Scheme 2013/2014

\section{Availability of data and materials}

All datasets that have led to the drawn deductions in the manuscript are herein presented in the paper.

\section{Ethics approval and consent to participate}

Not applicable, however, the farmers' and processors' meeting was in line with the usual extension service offered by the district agricultural production offices, whom the research team moved with.

\section{Consent for publication}

All authors consent the publications and permission to present the farmers' and processors' responses during the focus group discussions as well as questionnaire administration was verbally obtained.

\section{Competing interests}

All financial and material support for this research and work are presented in the funding section below. The authors and/or our affiliate institutions have no financial or any other relationship with the funding organization that inappropriately influenced or biased the research. Additionally, the authors declare no conflict of interest.

\section{Author details}

${ }^{1}$ College of Veterinary Medicine, Animal Resources and Biosecurity, Makerere University, Kampala, Uganda. ${ }^{2}$ VMT Consults (U) Limited, Plot 253 Kansanga, P.O. Box 29757, Kampala, Uganda. ${ }^{3}$ Department of Food Technology and Nutrition, School of Food Technology, Nutrition and Bioengineering, College of Agricultural and Environmental Sciences, Makerere University, Kampala, Uganda. ${ }^{4}$ Uganda Institute of Industrial Research, Ministry of Trade and Industry, Kampala, Uganda. ${ }^{5}$ ECOWAS-USAID Senior Sanitary and Phytosanitary (SPS) standards advisor, Abuja, Nigeria.

\section{Received: 21 May 2019 Accepted: 14 April 2020}

\section{Published online: 24 April 2020}

\section{References}

Afolabi CG, Ezekiel CN, Ogunbiyi AE, Oluwadairo OJ, Sulyok M, Krska R (2019) Fungi and mycotoxins in cowpea (Vigna unguiculata L) on Nigerian markets. Food Addit Contam: Part B 13(1):52-58. https://doi.org/10.1080/19393210. 2019.1690590

Akande K, Abubakar M, Adegbola T, Bogoro S (2006) Nutritional and health implications of mycotoxins in animal feeds: a review. Pak J Nutr 5(5):398-403. https://doi.org/10.3923/pjn.2006.398.403

Atukwase A, Kaaya AN, Muyanja C (2009) Factors associated with fumonisin contamination of maize in Uganda. J Sci Food Agric 89(14):2393-2398. https://doi.org/10.1002/jsfa.3734

Bankole S, Schollenberger M, Drochner W (2006) Mycotoxins in food systems in sub Saharan Africa: a review. Mycotoxin Res 22(3):163-169. https://doi.org/10. 1007/BF02959270
Cheat S, Oswald IP, Kolf-Clauw M (2016) Mycotoxin outbreak in animal feed. In: Foodborne diseases 2016. CRC press, Taylor and Francis Group, Boca Raton, USA. pp 270-299

Djekic I, Udovicki B, Kljusurić JG, Papageorgiou M, Jovanovic J, Giotsas C, Djugum J, Tomic N, Rajkovic A (2019) Exposure assessment of adult consumers in Serbia, Greece and Croatia to deoxynivalenol and zearalenone through consumption of major wheat-based products. World Mycotoxin J 12(4):431442. https://doi.org/10.3920/WMJ2019.2452

EFSA (2019) European Food Safety Authority; http://www.efsa.europa.eu/en/ topics/topic/aflatoxins. Accessed 21 Feb 2019

FAO (2004) "Worldwide regulation for mycotoxins in food and feed in 2003". Rome: Food and Agriculture Organization of the United Nations. FAO Food and Nutrition paper 81 Available: http://www.fao.org/3/y5499e/y5499e00.htm Accessed 15 May 2019

Hajnal EJ, Kos J, Malachová A, Steiner D, Stranska M, Krska R, Sulyok M (2020) Mycotoxins in maize harvested in Serbia in the period 2012-2015. Part 2: non-regulated mycotoxins and other fungal metabolites. Food Chem 317: 126409. https://doi.org/10.1016/j.foodchem.2020.126409

labal SZ, Jinap S, Pirouz AA, Ahmad Faizal AR (2015) Aflatoxin M1 in milk and dairy products, occurrence and recent challenges: a review. Trends Food Sci Technol 46(1):110-119. https://doi.org/10.1016/j.tifs.2015.08.005

Kaaya A, Warren H, Adipala E (2000) Moulds and aflatoxin contamination of maize and groundnuts in Mayuge and Kumi districts of Uganda. MUARIK Bull 3:33-41

Kaaya AN, Kyamuhangire W (2006) The effect of storage time and agroecological zone on mould incidence and aflatoxin contamination of maize from traders in Uganda. Int J Food Microbiol 110(3):217-223. https://doi.org/10.1016/j. ijfoodmicro.2006.04.004

Kaaya N, Warren H (2005) Review of past and present research on Aflatoxin in Uganda. Afr J Food, Agric Nutr Dev 5(1) https://wwwajfandnet/Nolume5/ No1/index1html Accessed 23 May 2014

Kajuna F, Temba B, Mosha R (2013) Surveillance of aflatoxin B1 contamination in chicken commercial feeds in Morogoro, Tanzania. Livest Res Rural Dev 25(3) http://www.Irrd.org/Irrd25/3/kaju25051.htm; Accessed 23 Apr 2019

Kana J, Gnonlonfin B, Harvey J, Wainaina J, Wanjuki I, Skilton R, Teguia A (2013) Assessment of aflatoxin contamination of maize, peanut meal and poultry feed mixtures from different agroecological zones in Cameroon. Toxins 5(5): 884-894. https://doi.org/10.3390/toxins5050884 Accessed 23 Apr 2019

Kang'ethe E, Lang'a K (2009) Aflatoxin B1 and M1 contamination of animal feeds and milk from urban centers in Kenya. Afr Health Sci 9(4):218-26.

Kotinagu K, Mohanamba T, Kumari LR (2015) Assessment of aflatoxin B1 in livestock feed and feed ingredients by high-performance thin layer chromatography. Vet World 8(12):1396. https://doi.org/10.14202/vetworld. 2015.1396-1399

Lanyasunya T, Wamae L, Musa H, Olowofeso O, Lokwaleput I (2005) The risk of mycotoxins contamination of dairy feed and milk on smallholder dairy farms in Kenya. Pak J Nutr 4(3):162-169

Leggieri MC, Lanubile A, Dall'Asta C, Pietri A, Battilani P (2020) The impact of seasonal weather variation on mycotoxins: maize crop in 2014 in northern Italy as a case study. World Mycotoxin J 13(1):25-36. https://doi.org/10.3920/ WMJ2019.2475

Lukwago FB, Mukisa IM, Atukwase A, Kaaya AN, Tumwebaze S (2019) Mycotoxins contamination in foods consumed in Uganda: a 12- year review (2006-2018). Scientific Afr:e00054. https://doi.org/10.1016/j.sciaf.2019.e00054

Makau CM, Matofari JW, Muliro PS, Bebe BO (2016) Aflatoxin B1 and Deoxynivalenol contamination of dairy feeds and presence of Aflatoxin M1 contamination in milk from smallholder dairy systems in Nakuru, Kenya. Int J Food Contam 3(1):6. https://doi.org/10.1186/s40550-016-0033-7

Marechera G, Ndwiga J (2014) Farmer perceptions of aflatoxin management strategies in lower eastern Kenya. J Agric Extension Rural Dev 6(12):382-392. https://doi.org/10.5897/JAERD14.0621

Milicevic D, Nesic K, Jaksic S (2015) Mycotoxin contamination of the food supply chain - implications for one health programme. Procedia Food Sci 5:187-190. https://doi.org/10.1016/j.profoo.2015.09.053

Moretti A, Logrieco AF, Susca A (2017) Mycotoxins: an underhand food problem. In: Mycotoxigenic Fungi. Humana press, New York, pp 3-12

Munthali W, Charlie H, Kachulu L, Seetha D (2016) How to reduce Aflatoxin contamination in groundnuts and maize a guide for extension workers. Monograph. ICRISAT, Patancheru, Telangana, India http://oar.icrisat.org/id/ eprint/9892, Accessed 15 May 2019 
Muzoora S, Khaitsa ML, Bailey H, Vuzi P (2017) Status on aflatoxin levels in groundnuts in Uganda. Pan Afr Med J 27(Supp 4):11. https://doi.org/10 11604/pamj.supp.2017.27.4.12453

Nemati Z, Janmohammadi H, Taghizadeh A, Nejad HM, Mogaddam G, Arzanlou M (2014) Occurrence of Aflatoxins in poultry feed and feed ingredients from northwestern Iran. Eur J Zool Res 3(3):56-60 https://www.

scholarsresearchlibrary.com/journals/european-journal-of-zoological-research Accessed 23 Apr 2019

Nyangi C, Mugula J, Beed F, Boni S, Koyano E, Sulyok M (2016) Aflatoxins and fumonisin contamination of marketed maize, maize bran and maize used as animal feed in northern Tanzania. Afr J Food, Agric, Nutr Dev 16(3):1105411065. https://doi.org/10.18697/ajfand.75.ILRI07

Ráduly Z, Szabó L, Madar A, Pócsi I, Csernoch L (2020) Toxicological and medical aspects of Aspergillus-derived Mycotoxins entering the feed and food chain. Front Microbiol 10:2908. https://doi.org/10.3389/fmicb.2019.02908

Sebunya TK, Yourtee DM (1990) Aflatoxigenic Aspergilli in foods and feeds in Uganda. J Food Qual 13(2):97-107. https://doi.org/10.1111/j.1745-4557.1990. tb00010.x

Stadler D, Berthiller F, Suman M, Schuhmacher R, Krska R (2019) Novel analytical methods to study the fate of mycotoxins during thermal food processing. Anal Bioanal Chem:1-8. https://doi.org/10.1007/s00216-019-02101-9

Streit E, Naehrer K, Rodrigues I, Schatzmayr G (2013) Mycotoxin occurrence in feed and feed raw materials worldwide: long-term analysis with special focus on Europe and Asia. J Sci Food Agric 93(12):2892-2899. https://doi.org/10. $1002 /$ jsfa.6225

Taligoola H, Ismail M, Chebon S (2010) Toxigenic fungi and aflatoxins associated with marketed rice grains in Uganda. J Basic Appl Mycol 1(1):45-52

Taligoola HK, Ismail MA, Chebon SK (2011) Mycobiota and aflatoxins associated with imported rice grains stored in Uganda. Czech Mycol 63(1):93-107

Udomkun P, Wiredu AN, Nagle M, Muller J, Vanlauwe B, Bandyopadhyay R (2017) Innovative technologies to manage aflatoxins in foods and feeds and the profitability of application - a review. Food Control 76:127-138. https://doi. org/10.1016/j.foodcont.2017.01.008

USFDA (2019) United States Food and Drug Administration. Guidelines for Aflatoxin levels. https://agriculture.mo.gov/plants/feed/aflatoxin.php visited 13th may 2019

Zain ME (2011) Impact of mycotoxins on humans and animals. J Saudi Chem Soc 15(2):129-144. https://doi.org/10.1016/j.jscs.2010.06.006

\section{Publisher's Note}

Springer Nature remains neutral with regard to jurisdictional claims in published maps and institutional affiliations.

Ready to submit your research? Choose BMC and benefit from:

- fast, convenient online submission

- thorough peer review by experienced researchers in your field

- rapid publication on acceptance

- support for research data, including large and complex data types

- gold Open Access which fosters wider collaboration and increased citations

- maximum visibility for your research: over $100 \mathrm{M}$ website views per year

At $\mathrm{BMC}$, research is always in progress.

Learn more biomedcentral.com/submissions 